\section{Nymphaea 'William Phillips', a New Intersubgeneric Hybrid}

\author{
Andrew S. Doran ${ }^{1}$, Donald H. Les, and Michael L. Moody \\ Department of Ecology and Evolutionary Biology, University of Connecticut, \\ Storrs, CT 06269-3043
}

\author{
William E. Phillips \\ 3049 East Glengarry Road, Memphis, TN 38128
}

Additional index words. Anecphya, Brachyceras, Nymphaea gigantea, Nymphaea 'Andre Leu', Nymphaea colorata, standard, water-lily

Hybridization has long been used as a means of producing new Nymphaea L. cultivars for ornamental ponds. Most Nymphaea hybrids involve interspecific crosses between closely related species, although more distant crosses were claimed (but not substantiated) by J.E. Planchon, W.E. Sturtevant, and W. Tricker (Conard, 1905). Notably, several intersubgeneric crosses in Nymphaea were reported by J.B. Latour-Marliac (subgenera Lotos DC. and Nymphaea) and O. Ames (subgenera Lotos DC. and Hydrocallis (Planch.) Conard) (Ames, 1900; Grey, 1900). However, Conard (1905) dismissed the validity of these claims due to a lack of evidence of pollen parentage and, in some cases, strong indications that traits were inherited from related species within the same subgenus.

A successful cross between Nymphaea subgenera has been verified recently using molecular genetic techniques (Les et al., 2004). This novel hybrid is newly described here as Nymphaea 'William Phillips' and not only represents the first proven intersubgeneric cross in the genus, but also is a tropical water-lily with highly desirable ornamental qualities.

\section{Origin}

Nymphaea 'William Phillips' A. Doran, Les \& M. Moody is a new and unique cultivar originating from an intersubgeneric cross (Les et al., 2004). This hybrid resulted from a controlled cross between the subgenera $A n$ ecphya Casp. and Brachyceras Casp., using $N$. gigantea Hook. 'Andre Leu' as the ovule parent and $N$. colorata Peter as the pollen parent. The cultivar name Nymphaea 'William Phillips' honors William E. Phillips, who first successfully achieved this intersubgeneric cross in 2002.

\section{Description}

Nymphaea 'William Phillips' is a tuberous, perennial, aquatic herb (Fig. 1; cover photo). Leaves are natant, subcoriaceous,

Received for publication 27 May 2003. Accepted for publication 23 Sept. 2003. We thank Michael Phillips and Virge Kask for technical and photographic assistance.

${ }^{1}$ To whom reprint requests should be addressed. E-mail address: adoran@uconnvm.uconn.edu and narrowly peltate with long petioles. Leaf blades are orbicular-ovate, 39-45 cm long, and $34-41 \mathrm{~cm}$ wide. The adaxial leaf surface is glossy and green [135C, Royal Horticultural Society (RHS), 1986]. The abaxial leaf surface is yellow-green (RHS 148D), suffused with greyed-red (RHS 181D), especially toward the margins. Leaf venation is centrally radiate, with 17-19 principal veins. Leaf margins are irregularly and broadly dentate with 5-7 teeth $/ 10 \mathrm{~cm}$. The marginal leaf teeth are $18-30$ $\mathrm{mm}$ wide and 9-15 $\mathrm{mm}$ deep. The leaf apex is obtuse; the basal lobes are acute and overlap the sinus.

Flowers are solitary, emergent, diurnal, and sweetly scented. They are intermediate between cupiform (cup-like) and stellate in shape. The four sepals are oblong, acute, $7-8 \mathrm{~cm}$ long, and $3-3.5 \mathrm{~cm}$ wide. Sepals are partially green (RHS 135C) and partially petaloid (RHS 96D-97A). There are $14-16$ petals, each $7.7-8.5 \mathrm{~cm}$ long and $2.3-3.3 \mathrm{~cm}$ wide, with an entire margin and obtuse apex. The transition of petals to stamens is relatively abrupt. Petals of first-day flowers are violet-blue (RHS 96D-97A). There
Fig. 1. Nymphaea 'William Phillips'. are $\approx 200$ stamens with carmine (RHS 64B) anthers that turn greyed-orange (RHS 174D) with age. Filaments are yellow (RHS 11D) centrally, turning to violet-blue (RHS 97C) peripherally, and fading to greenish-white (RHS 157D) with age. The filaments are $0.5-1.5 \mathrm{~mm}$ wide, the larger ones somewhat laminar. The floral axis is carmine (RHS 64B). The hybrid is distinct from the parents by its novel petal and anther colors and by its intermediate flower and petal shapes.

\section{Culture}

Nymphaea 'William Phillips' requires a constant water temperature of $27^{\circ} \mathrm{C}$ and full sunlight for optimal growth. Mature plants (1.8-3.0 $\mathrm{m}$ in diameter) require a $12-20 \mathrm{~L}$ container filled with aquatic plant growth medium. Plants should be kept submersed at a water depth of $45-60 \mathrm{~cm}$ above the container level. Plants are propagated vegetatively by harvesting the tubers produced at the end of the growing season. Dormant tubers are stored in damp sand at no less than $21^{\circ} \mathrm{C}$. This tropical hybrid can be grown outdoors as an annual where the daytime air temperature exceeds $26{ }^{\circ} \mathrm{C}$, and can be grown as a perennial when water temperatures are maintained near $27^{\circ} \mathrm{C}$, with air temperatures exceeding $21^{\circ} \mathrm{C}$. Water temperature and bright sunlight appear to be more critical than air temperature, because this plant still performs well when ambient air temperatures are 5 to $6{ }^{\circ} \mathrm{C}$ lower than water temperatures as long as high light intensities are maintained. Plants are hardy in U.S. Dept. of Agriculture (USDA) zone 11. In the lower USDA zones (5-9), the plants require supplemental high-pressure sodium or metal halide lighting equal to a 16-h day in addition to the warm water temperatures. Plants grown under these conditions will flower nearly continu-

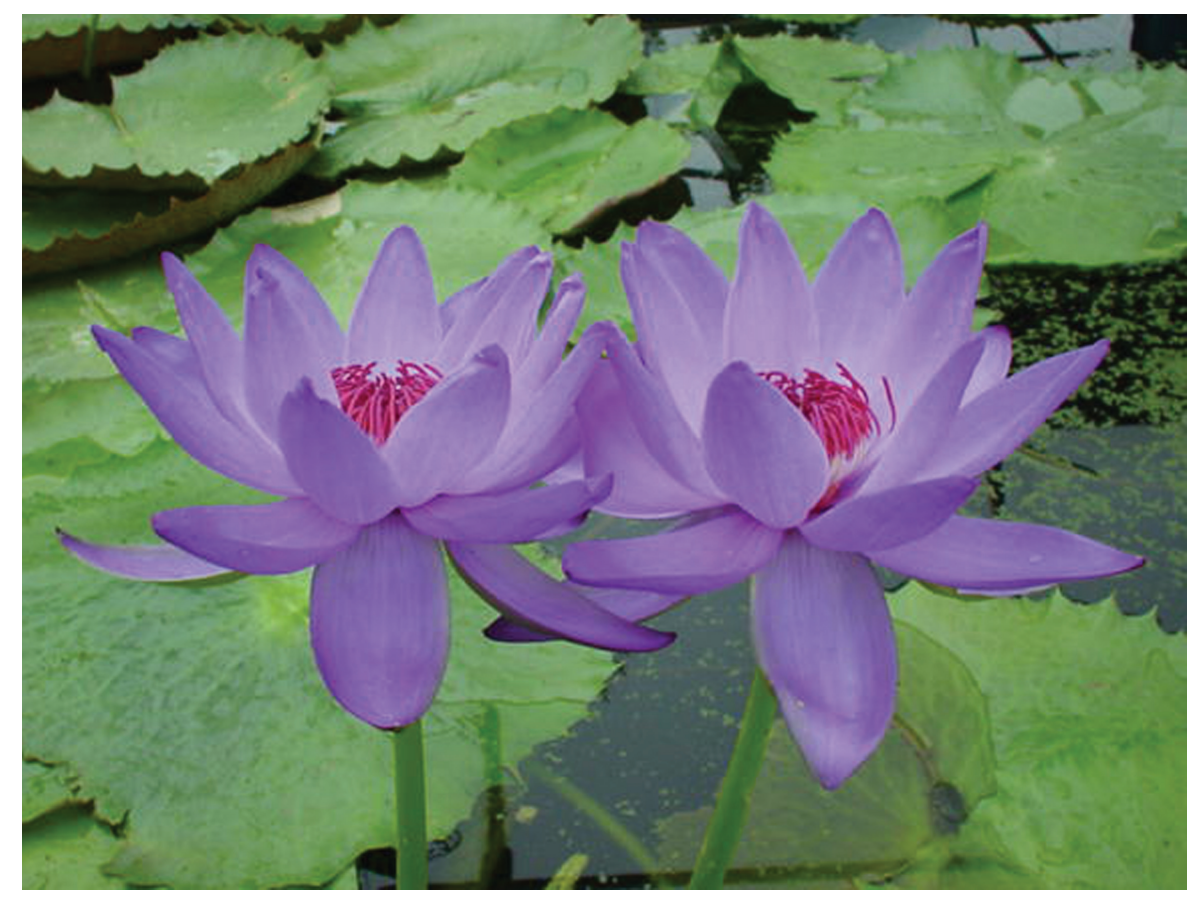


ously for several years. The lower portion of the rhizome should then be removed and the plant with its roots should be planted deeper into the soil. Any exposed roots should be covered with soil.

\section{Availability}

Plants will be distributed to major aquatic plant nurseries throughout the country. Further details can be acquired by contacting William E. Phillips. Plants cannot be produced from seed and have failed in crosses attempted with other Nymphaea. Therefore, tubers are the only practical means of increasing nursery stock.

\section{Standard}

The standard of Nymphaea 'William Phillips' comprises a set of five dried specimens (accession no. 121558) provided by the originator and conserved at the Univ. of Connecticut's George Safford Torrey Herbarium (CONN). The standard specimens were collected by William E. Phillips from growing tank no. 7, located at 1161 Stage Ave., Memphis, TN 38127. The standard portfolio also includes additional dried material for further destructive sampling, an illustration, digital and printed images, a copy of the International Waterlily and Water Garden Society (IWGS) registration form, and the protologue. The cultivar was originated by William E. Phillips and was nominated by Kit Knotts, Cocoa Beach, Fla.

The name Nymphaea 'William Phillips' was included inadvertently in a previous list (Knotts, 2002); however, that action did not constitute establishment of the name in accordance with Article 22.6 of the International Code of Nomenclature for Cultivated Plants (Trehane et al., 1995).

\section{Literature Cited}

Ames, O. 1900. An interesting group of new hybrid blooming Nymphaeas. Amer. Gard. 21:644.

Conard, H.S. 1905. The waterlilies: A monograph of the genus Nymphaea. Carnegie Inst., Washington, D.C.

Grey, R.M. 1900. New hybrid Nymphaeas. Amer. Gard. 21:516.

Knotts, K. 2002. The names of waterlilies. Publ. by the author

Les, D.H., A.S. Doran, M.L. Moody, and W.E. Phillips. 2004. A genetically confirmed intersubgeneric hybrid in Nymphaea L. (Nymphaeaceae Salisb.). HortScience 39:219-222.

Royal Horticultural Society. 1986. Colour chart of the Royal Horticultural Society of London in association with the Flower Council of Holland. Royal Hort. Soc., London.

Trehane, P., C.D. Brickell, B.R. Baum, W.L.A. Hetterscheid, A.C. Leslie, J. McNeill, S.A. Spongberg, and F. Vrugtman (eds.). 1995. International code of nomenclature for cultivated plants - 1995. Reg. Veg. 133. Quarterjack, Wimborne, U.K. 